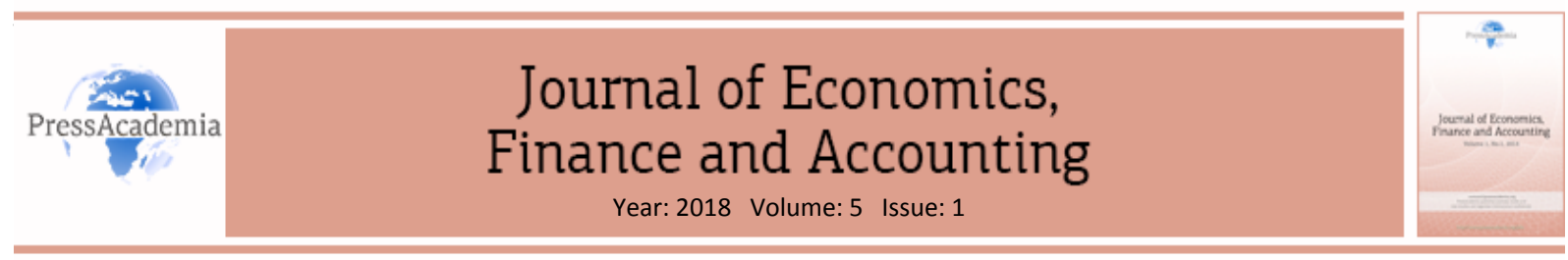

\title{
MODELING BRENT OIL PRICE WITH MARKOV CHAIN PROCESS OF THE FUZZY STATES
}

\author{
DOI: 10.17261/Pressacademia.2018.785 \\ JEFA- V.5-ISS.1-2018(7)-p.79-83
}

\author{
Ersin Kiral ${ }^{1}$ \\ ${ }^{1}$ Çukurova University. Department of Econometrics, Adana,01330, Turkey. \\ ekiral@cu.edu.tr ORCID ID: 0000-0001-6040-1795
}

\author{
To cite this document \\ (JEFA), V.5(1), p.79-83 \\ Permemant link to this document: http://doi.org/10.17261/Pressacademia.2018.785 \\ Copyright: Published by PressAcademia and limited licenced re-use rights only.
}

Kıral, E. (2018). Modeling brent oil price with markov chain process of the fuzzy states. Journal of Economics, Finance and Accounting

\begin{abstract}
Purpose - The rapid change of crude oil price in the international market has attacted several investors into examining price fluctuations. The estimation regarding to the exact monthly price of the brent oil has always been a diffucult task in the business sector.

Methodology - In this study, the directions of the monthly Brent oil prices from January 2003 to January 2017 are analyzed using the Markov Chains of Fuzzy States technique. In the first instance, the data are classified into twenty-one fuzzy states, and then calculated the probability transition matrix of the fuzzy states for the given period.

Findings- The directions of the monthly Brent oil prices are analyzed with transition matrix. Next the steady condition of the Brent oil return is obtained. These results give valuable information to decision makers regarding the investment opportunities of Brent oil for the short and long term marketing strategies.

Conclusion- In crucial months, when a monthly return increases or decreases significantly, the proceeding month's expected return also increase or decreases significantly. The proposed model can be used to estimate short term returns (one day) and also employing several fuzzy sets may give more investment opportunities.
\end{abstract}

Keywords: Brent oil price, Markov chains, Fuzzy logic, Fuzzy states of Markov chains JEL Codes: C44, C53, C61

\section{INTRODUCTION}

Oil, which is very important in economy, politics and technology, has been used for a long period of time for various objectives. Oil is still the most important energy source in the world and it is not expected to change in the next twenty years. Oil is very important for many industries and industrialized civilizations, for this reason it becomes one of the most important resources for many countries.

Brent Oil, the largest piece of the global economy, is the highest quality oil in the world after Texas Crude Oil. Brent Oil is a valuable raw material because it is a non-substitute scarce natural resource. It is rapidly affected by the developments that may occur in the political, economical and social agenda. The result of sudden price changes is among the high investment instruments. The price of Brent oil is the first choice on the commodity list of investors. It may be affected by the oil reserves of the governments, the policies of the producer countries and the stock quantities, and the investment policies of the oil companies. Among the factors affecting the price in the demand direction are the developments in the economy, the usage of the industry, the requirements of the transportation sector, global climate changes and changes in the demand for energy use. Oil prices can also be affected by increase or decrease in production among member countries of the Organization of Petroleum Exporting Countries (OPEC). It is also necessary to monitor the change in dollar prices due to the pricing in US dollars. Brent oil has been tested for the past two decades with a historical minimum of $\$ 9.55$ per barrel in 1998 and a historic maximum of \$147.5 per barrel in 2008.

Apart from being energy and industrial product, oil is a speculative investment tool. The price of oil in the market is determined by supply and demand balance and can be invested in oil based on Brent oil. 
According to the 1998 data published by the International Energy Agency, $35.7 \%$ of the global energy requirement is met by petroleum. The price of Brent oil is an important indicator for the world energy market and the price of $2 / 3$ of world oil supply is determined according to Brent oil. The Brent oil price is used as a reference especially in the trading of oil of Europe, Africa and Middle East with Western Countries.

The modeling and estimation of crude oil price is among the most important topics in the economic area because of its high return. Therefore, various studies have been conducted by many researchers to forecast the direction of the oil price. For instance, Sadorsky (2006), Narayan and Narayan (2007), and Gileva (2010) used GARCH model and its variants in order to model the volatility of oil price. Xie et al. (2006), proposed the support vector machine (SVM) model, and they use it to compare prediction efficiency with the conventional time series models. They showed that the SVM has better prediction efficiency than the ARIMA model and the back-propagation neural network (BPNN). Guo and Zhang (2012) conducted a study using genetic algorithm (GA) SVM, and proved that its forecasting performance exceeds that of the conventional SVM.

In this study, the probabilistic transition matrix of the closing returns of Brent oil prices are calculated using Markov Chain Model of Fuzzy States (MCFS). This method is used for obtaining the data while system moves between bounds of the states. Compared to classical Markov Chain technique, it is a more realistic and flexible technique. The present study can therefore suggests that investors can get valuable signal about the Brent oil price changes through the use of MCFS.

The remaining of the article is organized as follows: literature summary in the second section, data and method in the third section, findings and discussions in the fourth section, conclusion in the fifth section.

\section{LITERATURE REVIEW}

Fuzzy logic is a form of multi-valued logic that allow intermediate values in form of multi-valued logic, in which the truth values of variables maybe any number between 0 and 1 . Fuzzy logic is distinct in concept due to different interpretations involved where binary sets have true or false valued logic. The variables may have a truth-value that ranges in degree, where the truth values can range between completely true and completely false. Fuzzy logic is applied to improve the efficiency and simplicity of the systems.

Unlike Markov Chains alone, MCFS method has started to gain attentions of the researchers. People are beginning to understand the significance of Fuzzy Markov Chains and MCFS in decision-making. Research involving properties of Fuzzy Markov Chains and applications of Fuzzy States with Markov Chains methods include those conducted by Kruce et al. (1987), Yoshida (1994), Avrachenkov and Sanchez (2000), Kuranoa et al. (2006), Pardo and Fuente (2010), Vajargah and Gharehdaghi (2012), Zhou et al. (2013), Uzun and Kıral (2017).

MCFS model can be used to define the problem with fuzzy states when there are lack of information about the system or when the states of the system are obvious, but the number of the states is too large to make a decision (Pardo and Fuente, 2010).

In the real world situations, it is very difficult to collect crisp data. Moreover, the bounds of the system states are not crisp to analyze and make a good decision. Therefore, using Fuzzy sets allows the decision maker to define the problem under ambiguous conditions.

MCFS are the expansion of the Markov Chains to the fuzzy states which can be denoted by fuzzy sets. It is a model based on the probabilistic transition of the vague states, which can allow more flexible modeling to the decision maker than the classical probabilistic approach with crisp states.

Kıral and Uzun (2017) classified the daily returns of the Borsa Istanbul (BIST 100) data by using fuzzification and they obtained the transition matrix of the fuzzy states. In this study, Fuzzy states of the Markov chains has been defined and used for the prediction of the returns of the stock market. They predicted the daily stock returns for randomly chosen days and compared with classical Markov model. These study shows that MCFS provides a higher forecasting accuracy to the investors compared to MC model.

In this study Kıral and Uzun (2017)'s method is used for obtaining the direction of the Brent oil price. The above-mentioned methodology was used by the author to predict the direction of the gold price movement.

This investigation first classified the monthly closing returns of the oil prices as fuzzy states with the triangular fuzzy sets and then obtained the probability transition matrix of the fuzzy states and showed the steady condition of the oil price return. 


\section{DATA AND METHODOLOGY}

The study includes monthly data from January 2003 to January 2017. The monthly weighted average of the Brent oil price (US\$/barrel) was received from ("Investing.com", 2018).

The returns $R_{t}$ were calculated as a monthly percentage change of the Brent oil price:

$P_{t} ; R_{t}=\left(P_{t}-P_{t-1}\right) / P_{t-1}$,

where $t$ denotes the sessions $(t=2,3, \ldots, 167)$.

The average returns for the given period; $\mu_{R}$ is $0,80 \%$ and the standard deviation is $8,9 \%$ which is 11 times higher than the expected return.

\section{FINDINGS AND DISCUSSIONS}

Monthly percentage changes of the Brent oil price are classified with 21 fuzzy states from the high loss $S_{-10}$ to high return $S_{10}$ (see in Figure 1). Triangular fuzzy sets are used to define the states and calculate the membership degree of $R_{t}$ for each month for the period given.

Figure 1: Fuzzy states for Brent oil price return

$\mu$

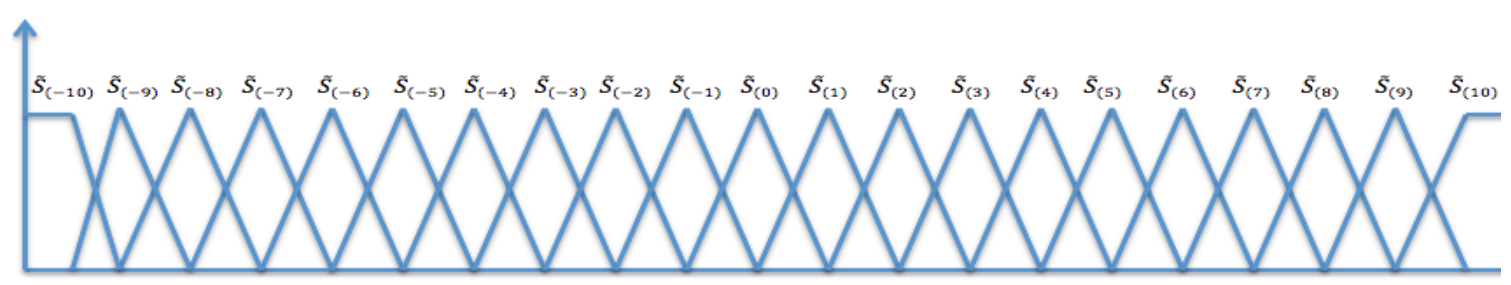

Fuzzy state components of the $R_{t}$ are defined as $\tilde{S}_{i}$ and $\tilde{S}_{i+1}$ and calculated as following function:

$$
\begin{aligned}
& >\quad \text { If }-2.25 \%<R_{t}<2.25 \% \text { then } i=\llbracket \frac{R_{t}}{0.225} \rrbracket \text { and } \\
& >\quad \tilde{S}_{i}=\frac{(i+1)\left(0.225-R_{t}\right)}{0.225}, \tilde{S}_{i+1}=1-\tilde{S}_{i} .
\end{aligned}
$$

$>$ If $R_{t} \leq-2.25 \%$ or $R_{t} \geq 2.25 \%$ then $\tilde{S}_{-10}=1$ or $\tilde{S}_{10}=1$ respectively.

Table1. Transformed Fuzzy States of The Gold Price Return for Some Months

\begin{tabular}{ll|lllllllllllllllllllll} 
Date & $R_{t}$ & $\tilde{S}_{-10}$ & $\tilde{S}_{-9}$ & $\tilde{S}_{-8}$ & $\tilde{S}_{-7}$ & $\tilde{S}_{-6}$ & $\tilde{S}_{-5}$ & $\tilde{S}_{-4}$ & $\tilde{S}_{-3}$ & $\tilde{S}_{-2}$ & $\tilde{S}_{-1}$ & $\tilde{S}_{0}$ & $\tilde{S}_{1}$ & $\tilde{S}_{2}$ & $\tilde{S}_{3}$ & $\tilde{S}_{4}$ & $\tilde{S}_{5}$ & $\tilde{S}_{6}$ & $\tilde{S}_{7}$ & $\tilde{S}_{8}$ & $\tilde{S}_{9}$ & $\tilde{S}_{10}$ \\
Jan. 2017 & $-1,97 \%$ & 0 & 0,76 & 0,24 & 0 & 0 & 0 & 0 & 0 & 0 & 0 & 0 & 0 & 0 & 0 & 0 & 0 & 0 & 0 & 0 & 0 & 0 \\
Dec. 2016 & $12,58 \%$ & 0 & 0 & 0 & 0 & 0 & 0 & 0 & 0 & 0 & 0 & 0 & 0 & 0 & 0 & 0 & 0 & 0 & 0 & 0 & 0 & 1 \\
Nov. 2016 & $4,49 \%$ & 0 & 0 & 0 & 0 & 0 & 0 & 0 & 0 & 0 & 0 & 0 & 0 & 0 & 0 & 0 & 0 & 0 & 0 & 0 & 0 & 1 \\
Oct. 2016 & $-1.55 \%$ & 0 & 0 & 0 & 0,89 & 0,11 & 0 & 0 & 0 & 0 & 0 & 0 & 0 & 0 & 0 & 0 & 0 & 0 & 0 & 0 & 0 & 0 \\
Sept. 2016 & $4,29 \%$ & 0 & 0 & 0 & 0 & 0 & 0 & 0 & 0 & 0 & 0 & 0 & 0 & 0 & 0 & 0 & 0 & 0 & 0 & 0 & 0 & 1
\end{tabular}

Table 1 shows the fuzzy states components of $R_{t}$ for some months.

After using conditional probability of the fuzzy state $\tilde{S}_{j}$, given the fuzzy state $\tilde{S}_{i}$, the transition probability of fuzzy states $\tilde{P}$ for the Brent oil return is calculated:

$\tilde{P}=$

$\begin{array}{lllllllllllllllllllll}\tilde{S}_{-10} & \tilde{S}_{-9} & \tilde{S}_{-8} & \tilde{S}_{-7} & \tilde{S}_{-6} & \tilde{S}_{-5} & \tilde{S}_{-4} & \tilde{S}_{-3} & \tilde{S}_{-2} & \tilde{S}_{-1} & \tilde{S}_{0} & \tilde{S}_{1} & \tilde{S}_{2} & \tilde{S}_{3} & \tilde{S}_{4} & \tilde{S}_{5} & \tilde{S}_{6} & \tilde{S}_{7} & \tilde{S}_{8} & \tilde{S}_{9} & \tilde{S}_{10}\end{array}$

\begin{tabular}{c|ccccccccccccccccccccc|}
$\tilde{S}_{-10}$ &, 42 &, 01 &, 01 & 0 &, 01 &, 01 &, 01 &, 02 & 0 & 0 & 0 & 0 &, 04 &, 02 & 0 & 0 & 0 & 0 & 0 & 0 &, 45 \\
$\tilde{S}_{-9}$ &, 45 & 0 & 0 & 0 & 0 & 0 & 0 & 0 & 0 & 0 & 0 & 0 & 0 & 0 & 0 & 0 & 0 &, 08 &, 37 & 0 &, 10 \\
$\tilde{S}_{-8}$ &, 57 & 0 & 0 & 0 & 0 & 0 & 0 & 0 & 0 & 0 & 0 & 0 & 0 & 0 & 0 & 0 & 0 &, 03 &, 12 & 0 &, 28 \\
$\tilde{S}_{-7}$ &, 42 & 0 & 0 & 0 & 0 & 0 & 0 & 0 & 0 & 0 & 0 & 0 & 0 & 0 & 0 & 0 & 0 & 0 & 0 & 0 &, 58
\end{tabular}




\begin{tabular}{c|cccccccccccccccccccccc}
$\tilde{S}_{-6}$ &, 49 & 0 & 0 & 0 & 0 & 0 & 0 & 0 & 0 & 0 & 0 &, 27 &, 11 & 0 & 0 & 0 & 0 & 0 & 0 & 0 &, 13 \\
$\tilde{S}_{-5}$ &, 30 & 0 & 0 & 0 & 0 & 0 & 0 & 0 & 0 & 0 & 0 &, 25 &, 10 & 0 & 0 & 0 & 0 & 0 & 0 & 0 &, 35 \\
$\tilde{S}_{-4}$ &, 06 & 0 & 0 & 0 & 0 & 0 & 0 & 0 & 0 & 0 & 0 & 0 & 0 & 0 & 0 & 0 & 0 & 0 & 0 & 0 &, 94 \\
$\tilde{S}_{-3}$ &, 30 & 0 & 0 & 0 & 0 & 0 & 0 & 0 & 0 & 0 & 0 & 0 &, 13 &, 18 & 0 & 0 & 0 & 0 & 0 & 0 &, 39 \\
$\tilde{S}_{-2}$ & 0 & 0 & 0 & 0 & 0 & 0 & 0 & 0 & 0 & 0 & 0 & 0 &, 42 &, 58 & 0 & 0 & 0 & 0 & 0 & 0 & 0 \\
$\tilde{S}_{-1}$ &, 15 & 0 & 0 & 0 & 0 & 0 & 0 & 0 & 0 & 0 & 0 & 0 & 0 & 0 & 0 & 0 & 0 & 0 & 0 & 0 &, 85 \\
$\tilde{S}_{0}$ &, 64 & 0 & 0 & 0 & 0 & 0 & 0 & 0 & 0 & 0 & 0 & 0 & 0 & 0 & 0 & 0 & 0 & 0 & 0 & 0 &, 36 \\
$\tilde{S}_{1}$ &, 32 & 0 & 0 & 0 & 0 & 0 & 0 & 0 & 0 & 0 & 0 & 0 & 0 &, 02 &, 02 &, 14 &, 15 & 0 & 0 & 0 &, 36 \\
$\tilde{S}_{2}$ & 0 & 0 & 0 & 0 & 0 & 0 & 0 & 0 & 0 & 0 & 0 & 0 & 0 &, 18 &, 19 &, 08 &, 06 & 0 & 0 & 0 &, 49 \\
$\tilde{S}_{3}$ &, 04 & 0 & 0 & 0 & 0 & 0 & 0 & 0 & 0 & 0 & 0 & 0 & 0 & 0 &, 31 &, 33 & 0 & 0 & 0 & 0 &, 33 \\
$\tilde{S}_{4}$ &, 50 & 0 & 0 & 0 & 0 & 0 & 0 & 0 & 0 & 0 & 0 & 0 & 0 & 0 &, 08 &, 08 & 0 & 0 & 0 & 0 &, 33 \\
$\tilde{S}_{5}$ &, 24 & 0 & 0 & 0 & 0 & 0 & 0 & 0 & 0 & 0 & 0 & 0 & 0 & 0 & 0 & 0 & 0 & 0 & 0 & 0 &, 76 \\
$\tilde{S}_{6}$ & 0 & 0 & 0 & 0 & 0 & 0 & 0 & 0 & 0 & 0 & 0 & 0 & 0 & 0 & 0 & 0 & 0 & 0 & 0 & 0 & 1 \\
$\tilde{S}_{7}$ & 0 & 0 & 0 & 0 & 0 & 0 & 0 & 0 & 0 & 0 & 0 & 0 & 0 & 0 & 0 & 0 & 0 & 0 & 0 & 0 & 1 \\
$\tilde{S}_{8}$ & 0 & 0 & 0 & 0 & 0 & 0 & 0 & 0 & 0 & 0 & 0 & 0 & 0 & 0 & 0 & 0 & 0 & 0 & 0 & 0 & 1 \\
$\tilde{S}_{9}$ & 1 & 0 & 0 & 0 & 0 & 0 & 0 & 0 & 0 & 0 & 0 & 0 & 0 & 0 & 0 & 0 & 0 & 0 & 0 & 0 & 0 \\
$\tilde{S}_{10}$ &, 30 &, 02 &, 04 &, 03 &, 01 &, 02 &, 01 &, 03 & 0 &, 01 &, 02 &, 02 & 0 & 0 &, 02 &, 01 & 0 & 0 & 0 & 0 &, 47 \\
& & & & & & & & & & & & & & & & & & & & &
\end{tabular}

The conditional partition degree of transition from $\tilde{S}_{-2}$ to $\tilde{S}_{3}$ is easily calculated $\left(\tilde{P}\left(\tilde{S}_{3} \mid \tilde{S}_{-2}\right)=58 \%\right)$ by looking at the value of $\ln \tilde{P}$.

$$
(\tilde{P})^{5}=
$$

$\begin{array}{lllllllllllllllllllll}\tilde{S}_{-10} & \tilde{S}_{-9} & \tilde{S}_{-8} & \tilde{S}_{-7} & \tilde{S}_{-6} & \tilde{S}_{-5} & \tilde{S}_{-4} & \tilde{S}_{-3} & \tilde{S}_{-2} & \tilde{S}_{-1} & \tilde{S}_{0} & \tilde{S}_{1} & \tilde{S}_{2} & \tilde{S}_{3} & \tilde{S}_{4} & \tilde{S}_{5} & \tilde{S}_{6} & \tilde{S}_{7} & \tilde{S}_{8} & \tilde{S}_{9} & \tilde{S}_{10}\end{array}$

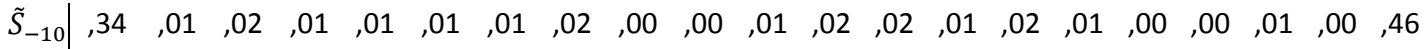

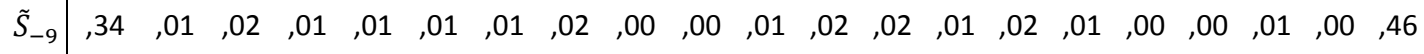

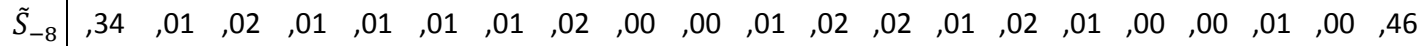

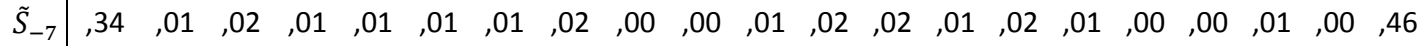

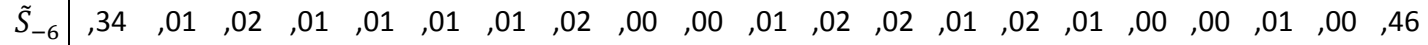

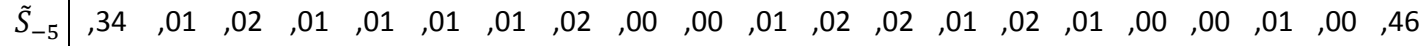

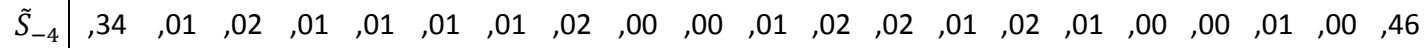

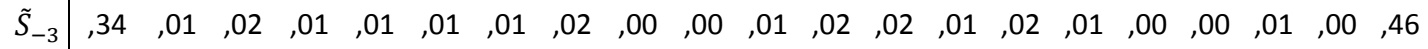

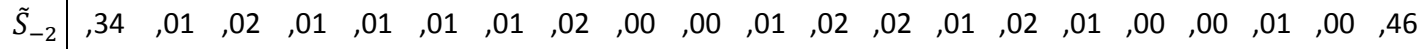

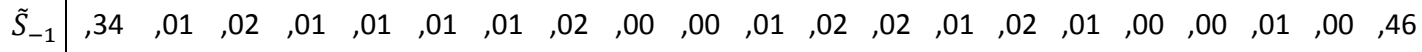

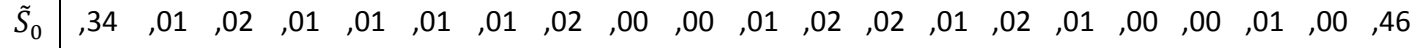

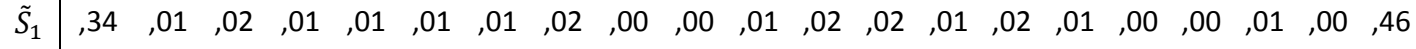

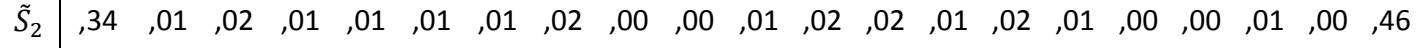

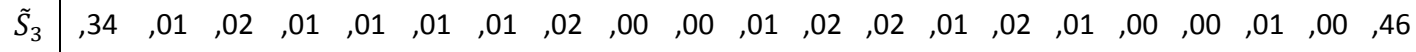

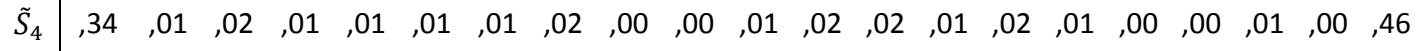

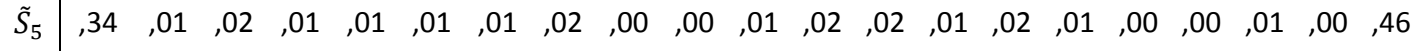

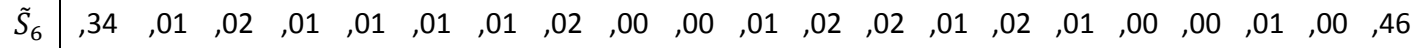

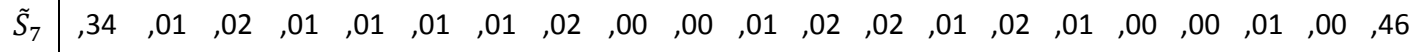

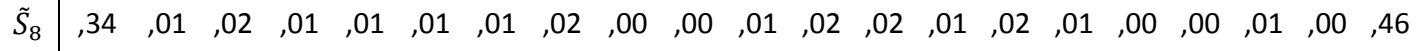

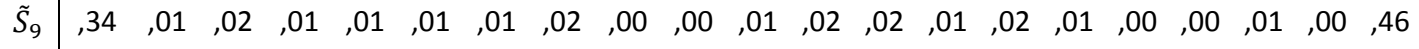
46

If a monthly return is in the states of $\tilde{S}_{6}, \widetilde{S}_{7}$, and $\tilde{S}_{8}\left(1.125 \%<R_{t}<2.025 \%\right)$; the proceeding month's return will increase by a value greater than or equal to $2.25 \%$. However, if the monthly return is in $\tilde{S}_{9,}\left(1.80 \%<R_{t}<2.25 \%\right)$; then the proceeding month's return is expected to decrease by a value greater than or equal to $2.25 \%$. It can be seen that it will be risky to invest to the Brent oil, if the monthly return is in the intersection interval of $\tilde{S}_{8}$ and $\tilde{S}_{9}\left(1.80 \%<R_{t}<2.025 \%\right)$. 
$\ln (\tilde{P})^{5}$, the conditional partition degree of 5 step transition can be seen

$$
\pi=
$$

$(.34, .01, .02, .01, .01, .01, .01, .02, .00, .00, .01, .02, .02, .01, .02, .01, .00, .00, .01, .00, .46)$

The steady condition of Brent oil return $(\pi)$, indicates that no matter the state of Brent oil return in a month, the number of gain months will be higher than the number of loss in 5 months. Excel-If Function was used for this calculation .

\section{CONCLUSION}

The directions of the monthly Brent oil price are analyzed with transition matrix. The results obtained give valuable information to decision makers regarding the investment opportunities of Brent oil for the short-term and long-term marketing strategies. In crucial months, when a monthly return increases or decreases significantly, the proceeding month's expected return also increase or decreases significantly. The proposed model can be used to estimate short term returns (one day) and also employing several fuzzy sets may give more investment opportunities. Investors can gain greater return in the long run according to the steady condition of Brent oil price.

\section{REFERENCES}

Avrachenkov K.E., Sanchez E., (2000). Fuzzy Markoc Chains. IPMU, 1851-1856.

Gileva, T., (2010). Econometrics of crude oil markets. Universite Paris 1. http://www.ebooks-for-all.com eBookEdition:2010.

Guo, X., Li, D. \& Zhang, A., (2012). Improved support vector machine oil price forecast model based on genetic algorithm optimization parameters. AASRI Procedia 1, 525-530.

Investing.com, (2018). www.investing.com. Retrieved 5 February 2018, from https://www.investing.com.

Kıral E., Uzun, B., (2017). Forecasting Closing Returns of Borsa Istanbul Index with Markov Chain Process of the Fuzzy States. Journal of Economics, Finance and Accounting 4(1), 15-23.

Kruce, R., Buck- Emden, R., Cordes, R., (1987). Process or Power Considerations: An Application to Fuzzy Markov Chains. Fuzzy Sets and Systems, 289-299.

Kuranoa, M., Yasuda, M., Jakagami, J., Yoshida, Y., (2006). A Fuzzy Approach to Markov Decision Processes with Unceratin Transition Probabilities. Fuzzy Sets and Systems 157, 2674-2682.

Narayan, P. K. \& Narayan, S., (2007). Modelling oil price volatility. Energy Policy 35(12), 6549-6553.

Pardo, M.J., Fuente, D., (2010). Fuzzy Markovian Decision Processes: Application to Queueing Systems. Computers and Mathematics with Applications." 60, 2526-2535.

Sadorsky, P., (2006). Modeling and forecasting petroleum futures volatility. Energy Economics 28(4), 467-488.

Uzun, B., Kıral, E., (2017). Application of Markov chains-fuzzy states to gold price. Procedia Computer Science, 120, 365-371.

Vajargah, B.F., Gharehdaghi, M., (2012). Ergodicity of fuzzy Makov chains based on simulation using Halton sequences. The Journal of Mathematics and Computer Science 4(3), 380-385.

Xie, W., Yu, L., Xu, S. \& Wang, S, (2006). A new method for crude oil price forecasting based on support vector machines. Computational Science-ICCS 2006'. Springer, 444-451.

Yoshida, Y., (1994). Markov chains with a transition possibility measure and fuzzy dynamic programming. Fuzzy Sets and Systems 66, 3957.

Zhou, X., Tang, Y., Xie, Y., Li, Y., Zhang, Y., (2013). A Fuzzy Probability- based Markov Chain Model for Electric Power Demand Forecasting of Beijing, China. Energy and Power Engineering, 488-492. 